\title{
A post-wildfire response in cave dripwater chemistry
}

\author{
Gurinder Nagra $^{1}$, Pauline C. Treble ${ }^{1,2}$, Martin S. Andersen ${ }^{1}$, Ian J. Fairchild ${ }^{3}$, Katie Coleborn ${ }^{1}$, and Andy Baker ${ }^{1}$ \\ ${ }^{1}$ Connected Waters Initiative Research Centre, University of New South Wales, Sydney, NSW, 2052, Australia \\ ${ }^{2}$ Institute for Environmental Research, Australian Nuclear Science and Technological Organisation, \\ Lucas Heights, NSW, 2234, Australia \\ ${ }^{3}$ School of Geography, Earth and Environmental Sciences, University of Birmingham, Edgbaston, Birmingham, UK
}

Correspondence to: Gurinder Nagra (g.nagra@unsw.edu.au)

Received: 3 January 2016 - Published in Hydrol. Earth Syst. Sci. Discuss.: 19 January 2016

Revised: 10 May 2016 - Accepted: 19 June 2016 - Published: 21 July 2016

\begin{abstract}
Surface disturbances above a cave have the potential to impact cave dripwater discharge, isotopic composition and solute concentrations, which may subsequently be recorded in the stalagmites forming from these dripwaters. One such disturbance is wildfire; however, the effects of wildfire on cave chemistry and hydrology remains poorly understood. Using dripwater data monitored at two sites in a shallow cave, beneath a forest, in southwest Australia, we provide one of the first cave monitoring studies conducted in a post-fire regime, which seeks to identify the effects of wildfire and post-fire vegetation dynamics on dripwater $\delta^{18} \mathrm{O}$ composition and solute concentrations. We compare our post-wildfire $\delta^{18} \mathrm{O}$ data with predicted dripwater $\delta^{18} \mathrm{O}$ using a forward model based on measured hydro-climatic influences alone. This helps to delineate hydro-climatic and firerelated influences on $\delta^{18} \mathrm{O}$. Further we also compare our data with both data from Golgotha Cave - which is in a similar environment but was not influenced by this particular fire - as well as regional groundwater chemistry, in an attempt to determine the extent to which wildfire affects dripwater chemistry. We find in our forested shallow cave that $\delta^{18} \mathrm{O}$ is higher after the fire relative to modelled $\delta^{18} \mathrm{O}$. We attribute this to increased evaporation due to reduced albedo and canopy cover. The solute response post-fire varied between the two drip sites: at Site 1a, which had a large tree above it that was lost in the fire, we see a response reflecting both a reduction in tree water use and a removal of nutrients $(\mathrm{Cl}, \mathrm{Mg}, \mathrm{Sr}$, and Ca) from the surface and subsurface. Solutes such as $\mathrm{SO}_{4}$ and $\mathrm{K}$ maintain high concentrations, due to the abundance of above-ground ash. At Site 2a, which was covered by lowermiddle storey vegetation, we see a solute response reflecting evaporative concentration of all studied ions $(\mathrm{Cl}, \mathrm{Ca}, \mathrm{Mg}, \mathrm{Sr}$,
\end{abstract}

$\mathrm{SO}_{4}$, and $\mathrm{K}$ ) similar to the trend in $\delta^{18} \mathrm{O}$ for this drip site. We open a new avenue for speleothem science in fire-prone regions, focusing on the geochemical records of speleothems as potential palaeo-fire archives.

\section{Introduction}

Caves are observatories, that preserve invaluable geochemical archives of past-climates; in the form of speleothems (stalagmites, stalactites and flowstones). The existing paradigm in speleothem science has largely focused on establishing palaeoclimate proxies in stalagmites (e.g. McDermott et al., 2001; Treble et al., 2008; Woodhead et al., 2010). While these proxies are useful for reconstructing palaeoclimates, their interpretations may hold a predisposed bias towards using these proxies as indicators of palaeoclimate only.

To avoid this bias, we need to consider the sensitivity of these proxies to the effects of local environmental factors like in our case, fire. This is especially important as incorporating this perspective may not only be used to correct the climate proxy interpretation, but also yield novel information about palaeo-environments. Palaeo-environmental proxies are verified by conducting process-based in-cave monitoring studies. However, in-cave monitoring has predominantly focused on understanding the extent to which dripwater $\delta^{18} \mathrm{O}$ (Lachniet, 2009), dripwater solute concentrations (Fairchild and Treble, 2009), speleothem calcite growth (Wong et al., 2011), and cave $\mathrm{CO}_{2}$ processes (Breecker et al., 2012), are affected by climate. Further, such studies have largely been restricted to mid- to high latitude climate regions where precipitation $(P)$ 
is larger than actual evapotranspiration (AET), and climate is likely to be a major control on dripwater composition.

In water-limited regions, dripwater chemistry is influenced to a greater extent by environmental factors such as evaporation (E) (Pape et al., 2010; Cuthbert et al., 2014; Rutlidge et al., 2014) and transpiration ( $T$ ), (Tremaine and Froelich, 2013; Treble et al., 2016). Wildfires, common in waterlimited regions, are agents of change that can dramatically alter evaporation and transpiration rates by destroying vegetation. The potential impacts of vegetation loss from fire are both short-term and long-term. The short-term impacts could include (1) an increase in evaporation rates due to changes in albedo and/or lack of shading (Silberstein et al., 2013); (2) a reduction in transpiration from reduced tree water use; (3) a reduction in soil microbial and root $\mathrm{CO}_{2}$ production (Coleborn et al., 2016); (4) a decrease in cave $\mathrm{CO}_{2}$ due to the destruction of vegetation (Wong and Banner, 2010), which could influence in-cave prior calcite precipitation (PCP); (5) the addition of plant ash to the soil profile, increasing concentrations of $\mathrm{Ca}, \mathrm{K}, \mathrm{Mg}$, and $\mathrm{S}$ (Grove et al., 1986; Yusiharni and Gilkes, 2012a); and (6) altered infiltration patterns (González-Pelayo et al., 2010). The long-term impacts include (1) the spatial redistribution of nutrients (Abbott and Burrows, 2003); (2) regrowth impacts on water balance and nutrient flux (Treble et al., 2016); and (3) a reduction in total soil $\mathrm{CO}_{2}$ due to the destruction of $\mathrm{CO}_{2}$ sequestering microbial communities and plant roots, both significant sources of soil $\mathrm{CO}_{2}$ (Coleborn et al., 2016). Despite the fact that wildfires regularly affect water-limited regions, their impacts on $\delta^{18} \mathrm{O}$ and solute concentrations in cave dripwater have not been reported.

We analyse the composition of cave dripwater over 5 years (August 2005-March 2011) of cave monitoring in Yonderup Cave, a shallow cave system, in southwest Australia. Our monitoring followed an intense wildfire in February 2005 that burnt 1200 ha of Yanchep National Park. The fire was hot enough to calcine and fracture the limestone observed at the caves entrance (Fig. S1 in the Supplement). We compare our monitoring data to the regional groundwater geochemistry and published monitoring data (Treble et al., 2015) from Golgotha Cave in southwest Australia (lat. $36.10^{\circ} \mathrm{S}$, long. $115.05^{\circ} \mathrm{E}$ ). Our analysis provides one of the first analyses of the response of dripwater $\delta^{18} \mathrm{O}$ and solute concentrations to post-wildfire conditions in shallow caves located in the tree rooting zone.

\section{Site description}

Our study was conducted in Yonderup Cave in Yanchep National Park (lat. $31.5475^{\circ} \mathrm{S}$, long. $115.6908^{\circ} \mathrm{E}$ ), $20 \mathrm{~km}$ north of Perth, southwestern Australia (Fig. 1a). This region has a Mediterranean climate characterized by dry hot summers and cold wet winters with a 25-year (1990 to 2015) average annual surface temperature of $15.1^{\circ} \mathrm{C}$ and rainfall of
$664 \mathrm{~mm}$ with $85 \%$ of rainfall falling between May and October. Yonderup Cave is located in the young Quaternary Tamala Limestone Formation, a porous, partially lithified calcareous coastal dune sand. This karst process is said to be "syngenetic" with karstification occurring simultaneously with lithification of the host rock (Jennings, 1964; Fairchild and Baker, 2012).

Yonderup Cave is situated in a tuart forest (Eucalyptus gomphocephala), with mature tuart trees $30 \mathrm{~m}$ high, and an understory of shrubs and trees standing 5-10 m high, Sheoak trees (Allocasuarina fraseriana) 5-15 m high, and Balga trees (Banksia attenuata, Banksia menziesii, Banksia grandis, Allocasuarina fraseriana, Xanthorrhoea pressii). Tree roots are exposed in the cave, both in the roof (fine roots), and cave floor (thick tap roots). In February 2005, the area above the cave was burnt in an intense wildfire (Fig. 1b; Department of Parks and Wildlife, personal communication, 2015), substantially modifying vegetation above the cave including the death of mature trees and complete removal of canopy and understorey.

Over the period of August 2005 to March 2011, two drip sites in Yonderup Cave (Site 1a and Site 2a), were monitored for their chemical and hydrological variations. These two sites are $22.8 \mathrm{~m}$ apart (Site $2 \mathrm{a}$ east of Site $1 \mathrm{a}, \sim 1 \mathrm{~m}$ slope towards the East), located at similar depths below the surface $(\sim 4 \mathrm{~m})$ within the same chamber $(\sim 7 \mathrm{~m}$ height $)$ and partially separated by a large boulder fall-in. We use an existing cave survey to determine the location of each cave drip site relative to the ground surface (Fig. 1c). A soil depth survey was conducted within $5 \mathrm{~m}$ of each site (Table S3 in the Supplement), along with visual vegetation/ground surface observations post-fire. Soil depths were measured every metre with a dynamic soil penetrometer in north, south, east and west directions and averaged soil depth above each site were calculated.

Site 1a, $30 \mathrm{~m}$ from the cave entrance, has a drip source within a large cluster of soda-straw stalactites known as the "Wheatfield" (Fig. S2b). This circular feature is approximately $1 \mathrm{~m}$ across and as it appears in an otherwise very sparsely decorated part of the ceiling, suggesting that it represents a focused flow path into the cave. The land surface above this site is flat with $70 \%$ coverage by shallow soil (average $124 \mathrm{~mm}$ thickness) and the remaining surface is exposed bedrock $(\sim 30 \%)$. A tuart tree, located directly above Site 1a, burnt and collapsed during the 2005 wildfire, which resulted in the entire removal of canopy cover above Site $1 \mathrm{a}$. No other trees are close enough to provide shade on the surface above Site 1a.

In contrast, Site $2 \mathrm{a}$ situated $50 \mathrm{~m}$ from the cave entrance is in a highly decorated part of the cave known as the "Cathedral" characterized by large icicle shaped stalactites. Above Site $2 \mathrm{a}$, the soil cover is thicker $(200 \mathrm{~mm})$ and more homogenous with no bedrock exposure, and no trees directly above; however, there is a partial canopy cover from adjacent trees $\sim 15 \mathrm{~m}$ away. 

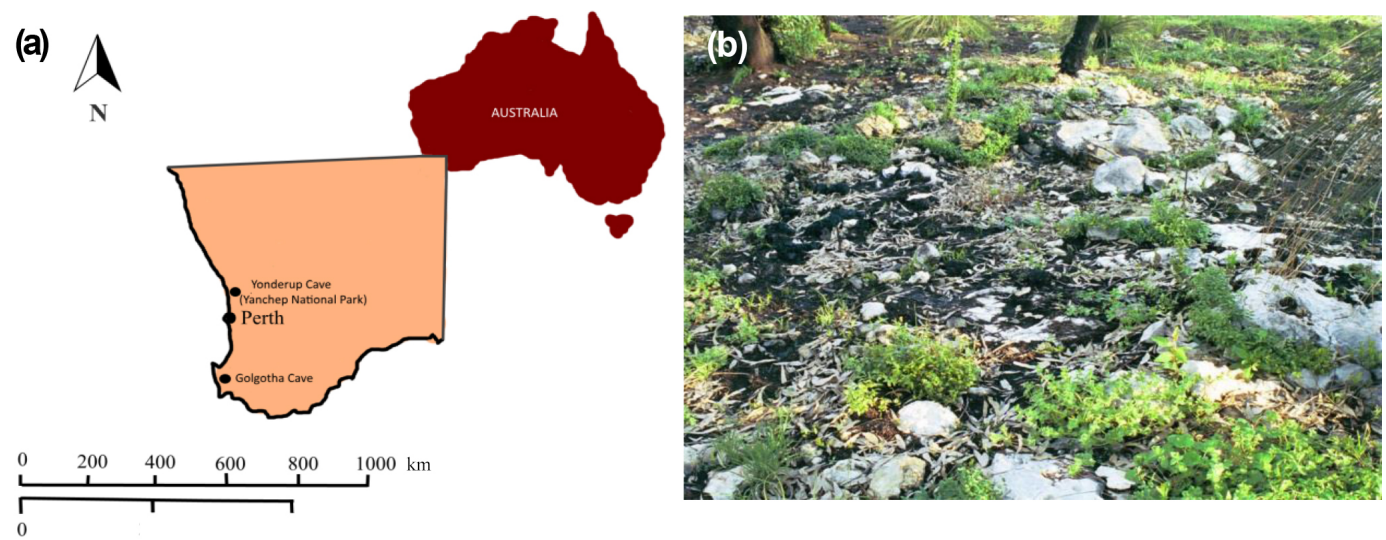

(c)

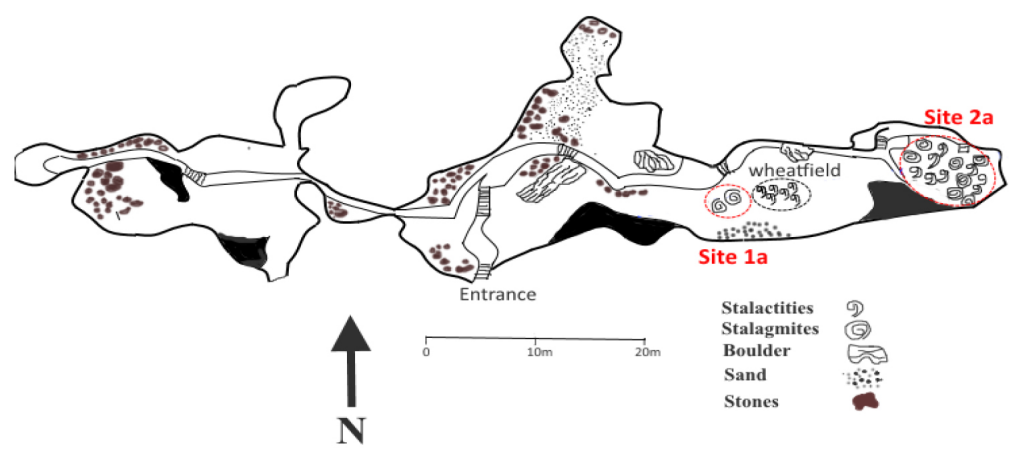

Figure 1. Geographical location of our study site (a), a post-fire photograph of the area (b) taken in August 2005 (a photo of recovering shrubs and grass post-wildfire), and (c) a map of Yonderup cave to scale originally surveyed by Watts and Henley (1973).

\section{Data collection}

Cave dripwater was collected from $1 \mathrm{~L}$ high-density polyethylene (HDPE) collection vessels at two sites Site 1a and Site 2a between August 2005 and March 2011 ( $\sim 5.5$ years) at approximately bi-monthly intervals. The water was separated into three aliquots: two aliquots were filtered with $0.45 \mu \mathrm{m}$ mixed-cellulose filters into two $50 \mathrm{~mL}$ polypropylene bottles for major and minor ion determination; the third was stored with zero-headspace in a $12 \mathrm{~mL} \mathrm{am}$ ber glass bottle for stable isotopes. All aliquots were refrigerated below $5{ }^{\circ} \mathrm{C}$ until analysis. Anion concentrations $(\mathrm{Cl}$ and $\mathrm{SO}_{4}$ ) were determined using a Dionex DX-600 ion chromatograph with self-regenerating suppressor on one aliquot. The second aliquot was acidified to $2 \% \mathrm{HNO}_{3}$ in the collection bottle and used for cation concentrations $(\mathrm{Ca}, \mathrm{K}, \mathrm{Mg}$, $\mathrm{Na}, \mathrm{Si}$ and $\mathrm{Sr}$ ) using a Thermo Fisher inductively coupled plasma atomic emission spectrometer (ICP-AES) ICAP7600 at the Australian Nuclear Science and Technology Organisation (ANSTO) facility. An internal standard with concentrations approximating the cave waters was included in each cation batch to check for between-run reproducibility.

Dripwaters collected between August 2005 and May 2008 were analysed for $\delta^{18} \mathrm{O}$ using isotope-ratio mass spectrometry (IRMS) at the Australian National University (see Tre- ble et al. (2013) for method). The remaining dripwaters were analysed for $\delta^{18} \mathrm{O}$ and $\delta^{2} \mathrm{H}$ at ANSTO using the cavity ringdown spectroscopy (CRDS) method. Additionally, as there was sufficient remaining water in the stored aliquots analysed by IRMS for Site $2 \mathrm{a}$, these were also re-analysed using CRDS to obtain a complete time series for $\delta^{2} \mathrm{H}$. After January 2007 dripwater volume at Site 1a became insufficient to collect all three aliquots. Collections of aliquots were prioritized in the following order: (1) stable isotopes, (2) cations, and (3) anions.

At each cave visit for dripwater sampling, drip rates were manually recorded using a stopwatch and the level of water accumulated in the bottles was recorded to the nearest $100 \mathrm{~mL}$. Weekly discharge was estimated using a drip volume of $0.2 \mathrm{~mL}$ per drip (Collister and Mattey, 2008). When timing drip intervals became impractical, only the bottle level was recorded. Thus, in order to represent the data in common units we needed to use the Collister and Mattey (2008) drip volume in order to convert all our discharge data into volume data. We use both sets of measurements from the overlapping period to convert volume to discharge for when direct measurements for drip interval using the stop watch were lacking. The calculations are provided in the supplementary info as excel sheets. 
To distinguish dry and wet periods, we applied a residual mass curve (RMC), (Hurst, 1951) to monthly $P$ - AET data. The RMC is the cumulative sum of the monthly anomaly calculated from the 22-year mean and used to generate a time series of cumulative potential water surplus or deficit starting from January 2000, highlights trends in above-average or below-average $P$ - AET, we refer to this calculation as cumulative water balance (CWB) throughout the rest of this paper.

Unpublished monthly $\delta^{18} \mathrm{O}$ and $\delta^{2} \mathrm{H}$ rainfall data (20052011) from Perth were obtained from ANSTO. We used modelled regional precipitation $(P)$ and actual evapotranspiration (AET/ $F_{\mathrm{WE}}$ is the sum of soil evaporation and transpiration by vegetation based on Priestly-Taylor equations) from the Australian Water Availability Project (AWAP) (Raupach et al., 2009, 2011) with monthly parameters, to determine $P$-AET. AWAP $P, \mathrm{AET} / F_{\mathrm{WE}}$, and rainfall $\delta^{18} \mathrm{O}$ data were then used as input to the forward model (detailed in the next section) to predict cave dripwater $\delta^{18} \mathrm{O}$ composition under various hydro-climatic scenarios. Predictions are based solely on $P$ - AET data, which are then compared to the dripwater observations.

Monthly rainfall $\delta^{18} \mathrm{O}$ and $\delta^{2} \mathrm{H}$ compositions were amount weighted and fitted with a linear regression (Hughes and Crawford, 2012) and compared to the long-term groundwater mean obtained from Turner and Thorpe (2001) and the cave dripwater to determine whether evaporation has affected cave dripwater isotopic composition (see Sect. 4).

Post-fire solute and $\delta^{18} \mathrm{O}$ data from Yonderup Cave dripwater are also compared to other relevant published data. These include, long-term Perth rainfall $\delta^{18} \mathrm{O}$ from Turner and Thorpe (2001), and local Yanchep rainfall solute data from Hingston and Gailitis (1976), and published dripwater data from Golgotha Cave, located $300 \mathrm{~km}$ south of Yanchep. Golgotha Cave has been monitored since 2005 (Treble et al., 2013; 2015, 2016; Mahmud et al., 2016). The climate at Golgotha Cave is also Mediterranean, but receives annual mean rainfall of $\sim 795 \mathrm{~mm}$, which is $23 \%$ higher than Yanchep. Both caves are located within the Tamala Limestone Formation; however, the caves vary in depths: Golgotha Cave is significantly deeper than Yonderup $\sim 30-35 \mathrm{~m}$. Golgotha Cave is covered by a more extensive forest of mixed marri/karri (Eucalyptus calophylla / Eucalyptus diversicolor) trees and this site has not experienced an intense wildfire since 1992 and no prescribed burns since 2006. We note, the prescribed burn at Golgotha Cave was much less intense and it was more controlled than the fire that is reported in our study.

\section{Forward model}

We use the forward model employed by Baker et al. (2010). This model uses monthly rainfall $\delta^{18} \mathrm{O}$, monthly $(P-\mathrm{AET})$ from 2003 to 2011 (we use 2003 to 2005 data as a "warmup" period to avoid edge effects), and adjustable bedrock flow thresholds for seepage flow and fracture flow to predict dripwater $\delta^{18} \mathrm{O}$ based on hydro-climatic influences. Seepage flow and fracture flow thresholds are hydrological $P-$ AET thresholds for the amount of infiltrating water that is required to enter seepage or fracture reservoirs (for further details see Baker and Bradley, 2010). The Tamala Limestone, retains high primary porosity thus seepage flow is likely to be dominant, whereas fracture flow is less dominant and only likely to be activated during high infiltration (Treble et al., 2013; Mahmud et al., 2016).

Water that enters the seepage reservoir is modelled as a Gaussian distribution. A maximum residence time of 3 years is set; this reflects the dominating seepage or matrix flow type at our site, the shallow depth $(4 \mathrm{~m})$ and the potential for capillary barrier effects to impact hydrology in this region (Mahmud et al., 2016). Further a minimum residence time of 10 months is required, to maintain the observed year round discharge at both sites. The model allows for the mean and standard deviation to be specified for these functions. Being conservative we specify the minimum residence time of $10 \pm 2$ months. In contrast, the fracture-fed flow is instantaneously passed through the system (i.e. with a travel time of less than 1 month). In the model we can adjust the ( $P-$ AET) thresholds required for flow into the seepage reservoir and the threshold required for it to spill into the fracture flow. The seepage and fracture-fed components are mixed in the overlying bedrock reservoir, before predicting dripwater $\delta^{18} \mathrm{O}$ composition. By request the authors can supply the forward model as a spread sheet.

We tested a full range of seepage and fracture possibilities. This suite of model runs helps to place constraints on $\delta^{18} \mathrm{O}$ variability that can be explained only by hydro-climatic variablity. We compare these scenarios to the observed dripwater $\delta^{18} \mathrm{O}$ at our sites, to assist in our interpretation of the post-fire dripwater $\delta^{18} \mathrm{O}$ response.

\section{Results}

A time series of monthly $P-$ AET, CWB, discharge, dripwater $\delta^{18} \mathrm{O}$, and ion concentrations for Sites 1a and 2a from August 2005 to March 2011 is shown in Fig. 2.

\subsection{Water balance}

First, we observe a distinct seasonality in the water availability ( $P$-AET) (Fig. 2a), where winter months generate an excess $(P>$ AET $)$, while summer months generate a deficit $(P<$ AET). Further, CWB shows three distinct trends throughout the monitoring period: (1) a decline over the period of January 2006 to June 2006, consistent with very low excess in $P$-AET; (2) an overall rise from June 2006 to February 2010; and (3) a decrease in $P$ - AET from February 2010 to September 2010. Sites 1a and 2a display moderate and similar discharge rates, at the start of the monitoring 

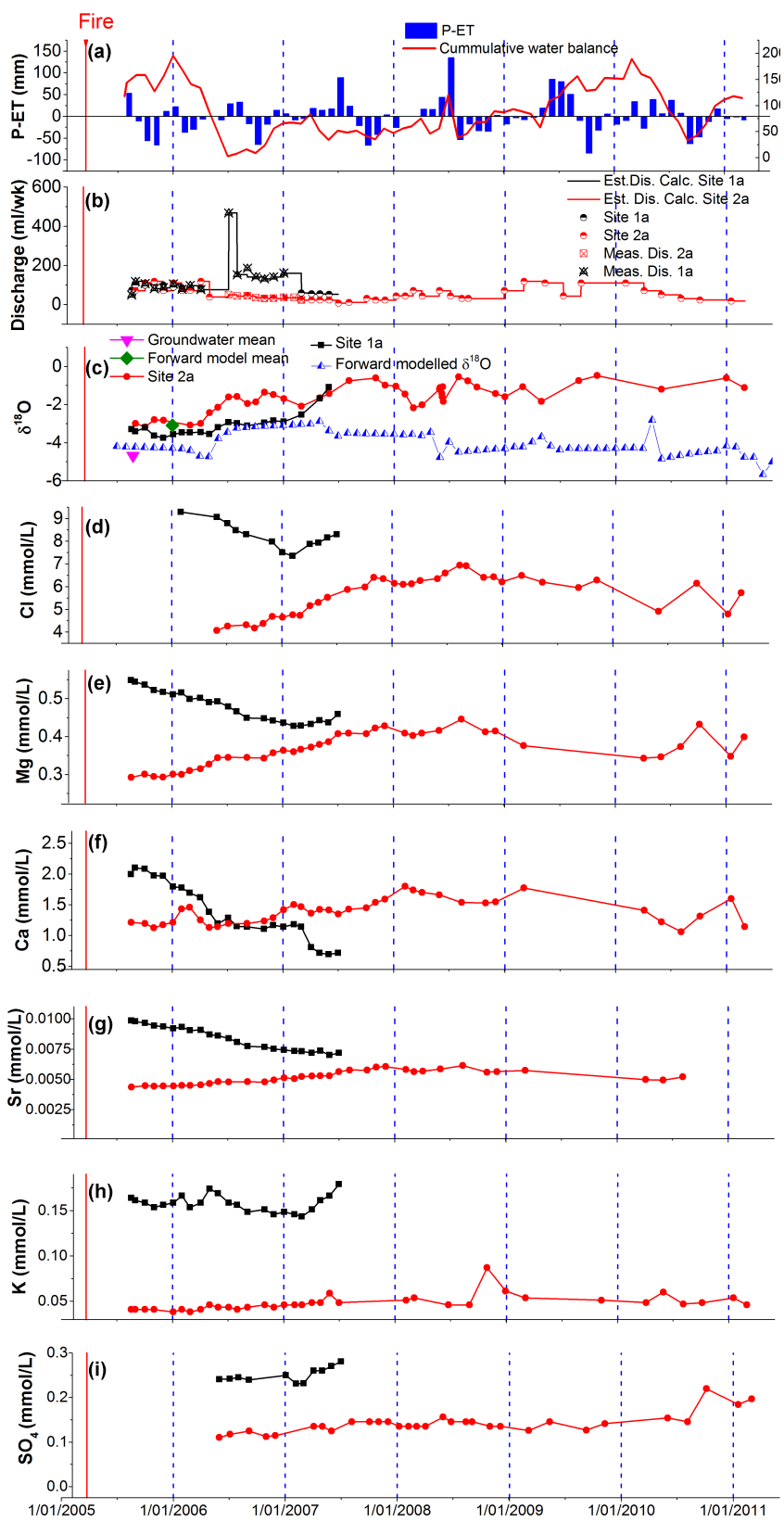

Figure 2. A post-fire time series of data from Site 1a and Site 2a. Note: Site 1a dries up in June 2007. (a) Precipitation - actual evapotranspiration $(P-$ AET), shows seasonal variations of excess (above threshold) and deficiency (below threshold) on a monthly scale overlayed with cumulative surface water balance. (b) Discharge is given in $\mathrm{mL}_{\text {week }}{ }^{-1}$. Actual measured discharge data are given in blue (Site $\left.1 \mathrm{a}\right)$ and black (Site 2a) while estimated data are given in red, which is then inferred to give measured discharge. Site 1a shows a spike in measured discharge in August 2006 and a consequent decrease until the site is dry, while Site 2a shows little variability in discharge throughout the monitoring period. (c) Shows observed $\delta^{18} \mathrm{O}$ composition of cave dripwater from Site 1a and Site 2a with the forward modelled $\delta^{18} \mathrm{O}$ (red), mean modelled $\delta^{18} \mathrm{O}$ (orange), and long-term groundwater $\delta^{18} \mathrm{O}$ mean (pink). (d) $\mathrm{Cl}$ declines at Site 1a until February where it shows a slight increase until the drip becomes dry, while Site 2a shows a steady increase until in July 2007 where it stabilizes for the remainder of the monitoring period. (e) Post-fire response shows a decline in Mg at Site 1a until dry and a steady increase at Site 2a until in December 2007 where it remains stable. (f) Site 1a shows stepwise decline in Ca at Site 1a until dry, while at Site 2a a very gradual increase until June 2007 is seen while the remainder of the monitoring period remains steady. (g) Response for Sr shows Site 1a declining and Site 2a peaking in December 2007; an identical response to $\mathrm{Mg}$ and at both sites. (h) K post-fire at Site 1a shows high concentrations, triple that of Site 2a but stable, while at Site $2 \mathrm{a}$ shows a slight increase over time. (i) $\mathrm{SO}_{4}$ both Site 1a and Site $2 \mathrm{a}$ show a slight increasing trend over time. But Site 1a has more than double the initial absolute concentration in comparison to Site 2a, similar to other solutes. 


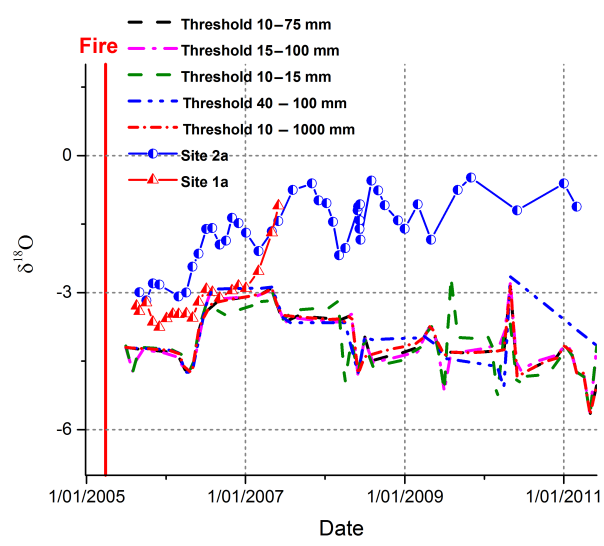

Figure 3. Modelled dripwater $\delta^{18} \mathrm{O}$ outputs under varying thresholds in our forward model (model from Baker et al., 2010) which accounts for climatic and various epikarst threshold values that control isotopic values. Given no output matches observed dripwater composition, we can infer that a localized factor has influenced isotopic compositions.

period that continue until July 2006; Site 1a has an average of $90 \mathrm{~mL} \pm 21 \mathrm{~mL}$ per week while Site 2a has an average of $92 \mathrm{~mL} \pm 23 \mathrm{~mL}$ per week. This coincides with the positive CWB (Fig. 2b). In July 2006, Site 1a dramatically increased discharge 5 -fold to $468 \mathrm{~mL}^{\text {week }}{ }^{-1}$ on one cave visit, but decreased to $55 \mathrm{~mL} \pm 3 \mathrm{~mL}$ per week on the subsequent visit 2 weeks later and was completely dry, 3 months later. This site has not re-activated since (Department Parks and Wildlife, personal communication, 2015). Site 2a shows much less variation in discharge overall, but contains smooth long-term trends. Two periods of higher discharge are observed in August 2005 to May 2006 (average $92 \mathrm{~mL} \pm 23 \mathrm{~mL}$ per week) and April 2008 to February 2009 (average $93 \mathrm{~mL} \pm 29 \mathrm{~mL}$ per week), both coincide with positive trends in CWB.

\subsection{Water isotopes}

Dripwater $\delta^{18} \mathrm{O}$ from Site 1a (Fig. 2c) shows no seasonal pattern but we see a steady increase of $1 \%$ o to January 2007 , then a further steeper rise of $1.5 \%$ in June 2007, after which the drip ceases. Dripwater $\delta^{18} \mathrm{O}$ from Site $2 \mathrm{a}$ presents an overall increasing trend rising from $-3 \%$ oto $+0.7 \%$ over the monitoring period with a 6-month quasi-seasonal signal ( $\sim 2 \%$ orange) that peaks in cooler months (June to October) coinciding with infiltration from rainfall in wet months. We hypothesize that the $P<$ AET environment in drier summer months isotopically enriches soil water, but this only arrives at the cave when seepage thresholds are exceeded in periods of $P>$ AET (winter months).

We forward modelled our rainfall isotopic data in order to predict drip-water $\delta^{18} \mathrm{O}$ under various hydro-climatic scenarios (Fig. 3). Our sensitivity analyses of hydrological residence times and thresholds showed that seepage residence times, less than 10 months resulted in the seasonal cessa- tion of dripwater, which is not observed at our sites. Therefore, a minimum seepage residence time is required to match our observations. Further, seepage threshold values greater than $40 \mathrm{~mm}(P-\mathrm{AET})$ also resulted in the cessation of our drip site. Thus, seepage threshold must be below $40 \mathrm{~mm}$ $(P-\mathrm{AET})$ to match our observation. Next we varied the fracture threshold between 15 and $1000 \mathrm{~mm}$, the wide range reflecting our uncertainty over this parameter. However, we know that seepage flow is dominant at these sites (Mahmud et al., 2016). This suggests two things, first, the seepage threshold is low, second, the threshold required for water to "overflow" from the seepage reservoir to fracture reservoir must be significantly higher than the seepage threshold. We note that scenarios with a lower fracture threshold $(10-15 \mathrm{~mm})$ show high variability in comparison to sites with a seepage dominated flow and no fracture flow (10 $1000 \mathrm{~mm}$ ). Based on the variable morphology of stalactites and stalagmites at our sites, we interpret discharge to be a combination of seepage and fracture flow, but with seepage clearly dominating. Hence, we chose the $15-100 \mathrm{~mm}$ scenario to represent the hydrology at our cave site (Fig. 3). Our forward-modelled dripwater $\delta^{18} \mathrm{O}$ mean is $-4.1 \%$, slightly less than the mean of Perth rainfall $(-3.1 \%$ ). The time series of modelled dripwater $\delta^{18} \mathrm{O}$ (Fig. 2c) starts and remains at $\sim-4.2 \%$ until February 2006 where it dips slightly before rising sharply to $-3 \%$ where it remains steady until February 2007. Here it begins a stepwise decline; declining from February to March 2007 by $0.5 \%$ and remaining stable again until February 2008. It then shows a further steep decline in March 2008 to $-4.5 \%$, where it remains at approximately this value, albeit with a few small variations on timescales of months, until the end of the monitoring period.

In all meaningful modelled scenarios, i.e. ones that have full-year flow and test the full range of hydrological variability, estimated dripwater $\delta^{18} \mathrm{O}$ cannot replicate the higher observed dripwater $\delta^{18} \mathrm{O}$, which are +1 to $+3 \%$ o higher compared to modelled $\delta^{18} \mathrm{O}$ (Fig. 3). This clearly suggests another factor is affecting dripwater $\delta^{18} \mathrm{O}$ composition: likely near-surface evaporation.

To investigate an evaporation effect, we plot cave dripwater along the local meteoric water line (LMWL; weighted least squares regression) to test for isotopic enrichment (Fig. 4). Figure 4 shows that while the least squares regression (LSR) for cave dripwater falls within the standard error $( \pm 0.45 \%$ ) of the slope for the LMWL (weighted LSR), dripwater isotopic composition is concentrated towards heavier $\delta^{18} \mathrm{O}$ and $\delta^{2} \mathrm{H}$. These results are consistent with evaporation in a high humidity environment as has been observed in semi-arid cave environments elsewhere (e.g. Cuthbert et al., 2014). Adopting Cuthbert's classification, our data falls under a type 1 scenario reported in Cuthbert et al. (2014). In the type 1 scenario, $\delta^{18} \mathrm{O}$ and $\delta^{2} \mathrm{H}$ do not deviate from the LMWL but are shifted along the LMWL towards higher values (Fig. 4). This means that our data are similarly impacted by evaporation occurring in a high humidity environment. 


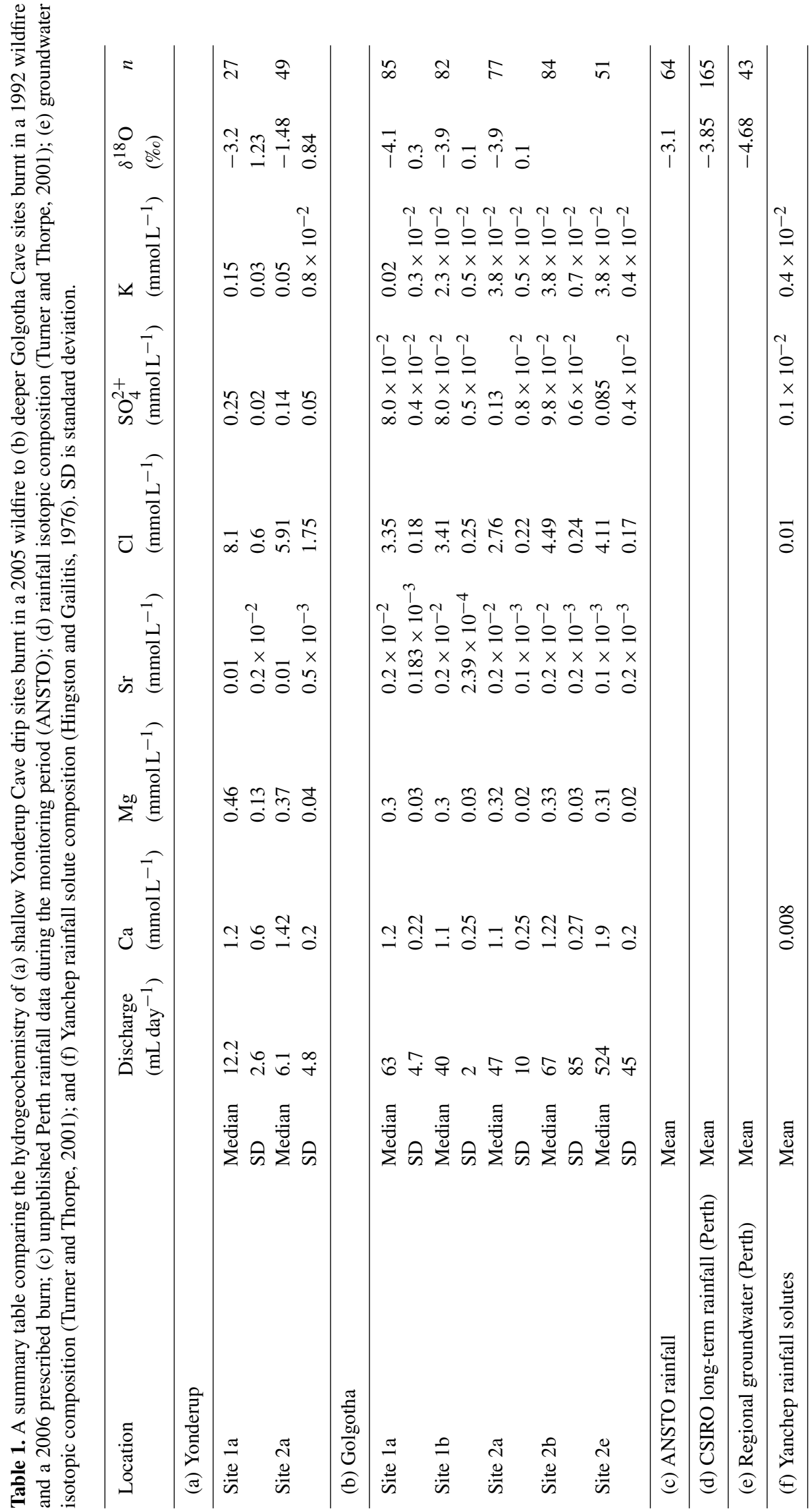




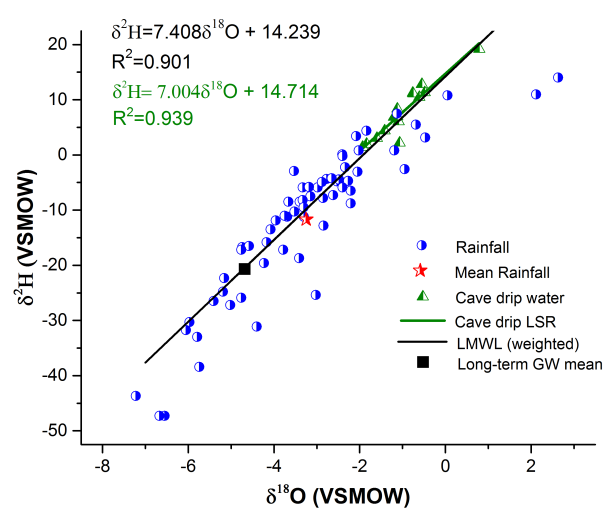

Figure 4. Shows compositions of $\delta^{2} \mathrm{H}$ against $\delta^{18} \mathrm{O}$ of our rainfall data (blue) during the monitoring period (ANSTO, unpublished), cave dripwater (red), long-term local groundwater mean (black) (0-10 ka, $n=43$, southern Perth Basin from Turner and Thorpe (2001)), and rainfall mean (red). A least squares regression (LSR) is plotted for cave dripwater (red line) and falls close to the local meteoric water line (LMWL, black), which is calculated using a weighted least squares regression (WLSR) using Hughes and Crawford (2012).

\subsection{Water solutes}

There are significant differences in solute concentrations and trends between the two sites (Fig. 2e-h). Solute concentrations are typically higher at Site 1a vs. Site $2 \mathrm{a}$ and they demonstrate opposite trends post-fire. At Site $1 \mathrm{a}, \mathrm{Cl}, \mathrm{Ca}, \mathrm{Mg}$, and $\mathrm{Sr}$ decline overall, although this trend is stepwise for $\mathrm{Ca}$, and reverses for $\mathrm{Cl} \sim 6$ months before the drip ceases. The trends in these solutes at Site 1a are inconsistent with the decline in CWB during this period (Fig. 2a), as we would expect a drying trend to reflect the evaporative concentration of solutes. In contrast at Site 2a, $\mathrm{Cl}$ and other solute concentrations show a direct relationship to CWB (i.e. increasing solute concentration with decreasing CWB from 2006 to mid2008 followed by decreasing solute concentrations with increasing CWB).

Trends in $\mathrm{SO}_{4}$ and $\mathrm{K}$ are more subtle than for other solutes: at Site 1a, K shows a slight decline from the beginning of the monitoring until early 2007 and then a small rise prior the drips ceasing. Although harder to judge in the shorter $\mathrm{SO}_{4}$ time series, $\mathrm{SO}_{4}$ also shows a small rise before drips cease, similar to $\mathrm{K}$. Trends in $\mathrm{K}$ and $\mathrm{SO}_{4}$ for Site $2 \mathrm{a}$ are more subtle, although they both increase slightly over time. K and $\mathrm{SO}_{4}$ concentrations are two to three times higher at Site 1a vs. Site 2a and are considerably higher than those recorded at Golgotha Cave (Table 1). We also note that initial $\mathrm{Cl}$ and other solute concentrations at Site 1a are twice that at Site 2a.

\section{Discussion}

\subsection{Post-fire hydrology}

Discharge at Site 1a is inconsistent with CWB: discharge rose as rainfall fell below the long-term mean $(P<\mathrm{AET})$ (Fig. 2a and b), suggesting that Site 1a received a localized increase in discharge despite the declining input from rainfall. In contrast, discharge at Site 2a is more closely related to the CWB, with higher discharge coinciding with periods of higher water surplus and lower discharge with lower water surplus.

Chloride is a chemically conservative and highly soluble solute (Graedel and Keene, 1996), its concentrations in dripwater will therefore reflect concentration/dilution effects (Tooth and Fairchild, 2003; Tremaine and Froelich, 2013). Chloride concentrations at Site 2a increase during the period of declining CWB (2006 to mid-2008) suggesting that evaporation is concentrating $\mathrm{Cl}$. Rising $\delta^{18} \mathrm{O}$ and other solutes over this period are also consistent with increased evaporation. From mid-2008 onwards, when CWB is positive $(P>$ AET), $\mathrm{Cl}$ decreases, consistent with an increase in infiltration and thus dilution (Fig. 2e).

At Site 1a higher discharge also coincides with falling $\mathrm{Cl}$ concentrations also suggesting dilution (Fig. $2 b$ and d). However, we note this high discharge coincides with a highly negative $\mathrm{CWB}$, i.e. drier than normal conditions. This suggests in this case, a non-climatic driver has influenced infiltration. We propose that a reduction in localized transpiration, following the 2005 fire, may be driving this. Deeply rooted trees within the area have been reported to produce high $\mathrm{Cl}$ concentrations in the unsaturated zone (Turner et al., 1987). Site 1a had a tuart tree directly above it and tree roots are visible above Site 1a in the cave, but not at Site 2a. The proximity of the tree to Site 1a is the most likely explanation for the higher solute concentrations here (Treble et al., 2016). The death of the tree in the 2005 fires would remove the previous transpiration demand and hence result in effective dilution of the solutes during infiltration, as observed. Although, this reduction in transpiration would have been abrupt but we observe a response lasting 1.5 years after the fire. This delay could be due to a number of reasons; first, the minimum residence time is 10 months (for a year of continuous discharge) so a delay in the response is to be expected. Second, this occurred during a period in which the soil moisture deficit would have been larger than average, so a larger volume of cumulative infiltration would be needed to overcome this deficit and move the more dilute solute into the cave.

It is also possible the decrease in concentrations reflect the diminishing element concentrations after an immediate flush of the more soluble ash-derived material (i.e. the tail of a solute pulse). However, post-fire, highly soluble solutes like $\mathrm{Cl}$, will still reflect dilution due to increased discharge. So, it is likely that we are seeing a decline in these elements due 
Table 2. Summary of differences in mean concentration of solutes and isotopic composition of solutes among sites at Yonderup and Golgotha caves. We see that $\mathrm{Cl}, \mathrm{SO}_{4}, \mathrm{~K}$, and $\delta^{18} \mathrm{O}$ values, at both sites are distinctly different. Specifically, the solutes have higher concentrations and $\delta^{18} \mathrm{O}$ is higher at Yonderup Cave in comparison to Golgotha Cave. SD is standard deviation.

\begin{tabular}{lrccccccc}
\hline \multicolumn{7}{c}{ Site differences } \\
\hline \\
\hline
\end{tabular}

to a combination of the removal of these nutrients from the surface and subsurface, as well as dilution.

In the broader context we look at the differences in $\mathrm{Cl}$ at Yonderup Cave vs. Golgotha Cave. Both caves are $\sim 5 \mathrm{~km}$ from the coastline, so they likely have a similar amount of $\mathrm{Cl}$ aerosol deposition. Yet, post-fire $\mathrm{Cl}$ values at Yonderup Cave are more than double the $\mathrm{Cl}$ concentrations from Golgotha Cave (Table 1). Further, within-cave variability in $\mathrm{Cl}$ concentrations at Yonderup Cave are twice that at Golgotha Cave (Table 2). While variations in vegetation density (along with wildfire history) may have some role to play in the difference in mean dripwater $\mathrm{Cl}$ at each location, the higher withincave variability at Yonderup Cave (Table 2), suggests a postfire setting increases variability in dripwater chemistry. The impact of this is discussed further and a conceptual model (Fig. 6) devised later in Sect. 6.3.

\subsection{Post-fire carbonate chemistry}

Similar to $\mathrm{Cl}$, concentrations of carbonate metals $(\mathrm{Mg}, \mathrm{Ca}$ and $\mathrm{Sr}$ ) at Site 1a also decrease; this reflects solutes being diluted due to reduced tree water use. However, we note that at Site 1a, Ca, for example, declines twice as much (in concentration, $\sim 75 \%)$ in comparison to $\mathrm{Cl}(\sim 30 \%)$. Thus, for $\mathrm{Ca}$ another mechanism along with dilution is required to explain its non-linear step-like decline (Fig. 2g).

There are a number of mechanisms that could influence post-fire $\mathrm{Ca}$ concentrations. First, we consider increased near-surface evaporation inducing prior calcite precipitation (PCP). Increased evaporation, can saturate solutes relative to calcite in karstic waters and promote degassing.
Further, evaporation will slow the flow and increase waterrock interaction times. Both of these conditions are ideal for PCP. Both our sites show evidence of PCP: the $\ln (\mathrm{Sr} / \mathrm{Ca})$ vs. $\ln (\mathrm{Mg} / \mathrm{Ca})$ slopes in our data agree with the diagnostic range for PCP (a slope of + or -0.88 ; Fig. 5b) (Sinclair, 2011). Expressed as a time series (Fig. 5a), we see $\ln (\mathrm{Sr} / \mathrm{Ca})$ and $\ln (\mathrm{Mg} / \mathrm{Ca})$ increase simultaneously with $\delta^{18} \mathrm{O}$ and $\mathrm{Cl}$ (Fig. 2), suggesting that evaporation is indeed the common driving mechanism inducing PCP at Site 1a. For further information on PCP processes we recommend the reader to Fairchild et al. (2000), Sinclair (2011), and Treble et al. (2015).

A second mechanism influencing post-fire Ca concentrations may be the addition of plant ash (Yusiharni and Gilkes, 2012a) and highly soluble $\mathrm{CaO}$ (produced by the burning of exposed surface rock to the fire; Yusiharni and Gilkes, 2012b). Further, it is possible that the Ca decline may also reflect a decrease in $\mathrm{Ca}$ being leached post-fire that may have followed an earlier spike in $\mathrm{Ca}$ concentrations from the above. The extent to which each process is affecting the $\mathrm{Ca}$ concentration is difficult to assess in our data, especially since our monitoring did not commence until 6 months after the fire, and processes such as PCP and the addition of $\mathrm{Ca}$ from plant ash are difficult to constrain.

We now consider other carbonate metals $(\mathrm{Mg}$ and $\mathrm{Sr})$ at Site 1a to further constrain our interpretation. We find $\mathrm{Mg}$ and $\mathrm{Sr}$ decline by $\sim 30 \%$ (in terms of relative concentration). Thus, it is likely that the same process affecting $\mathrm{Cl}$ is also affecting $\mathrm{Mg}$ and $\mathrm{Sr}$, i.e. dilution, a decline in leaching of biomass-sourced ash, or some combination of both. Ca concentrations decline by a relatively larger amount $(75 \%)$ 


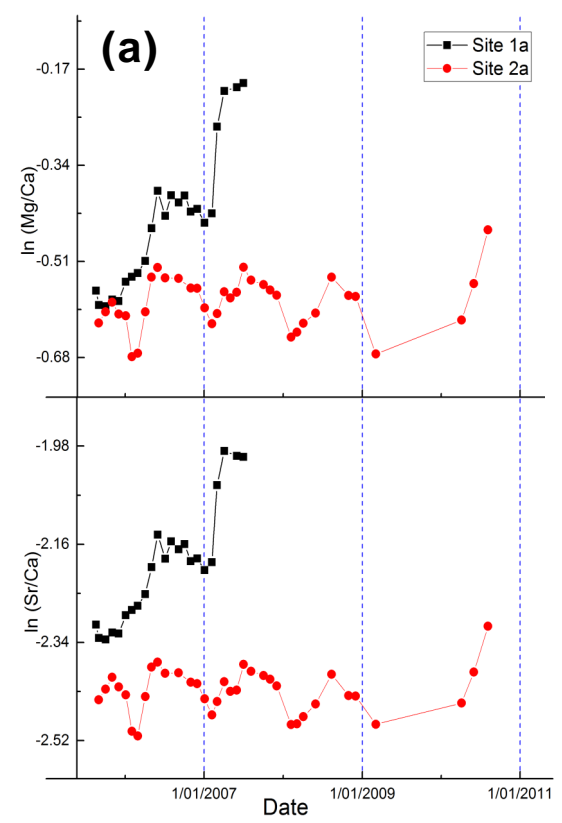

(b)

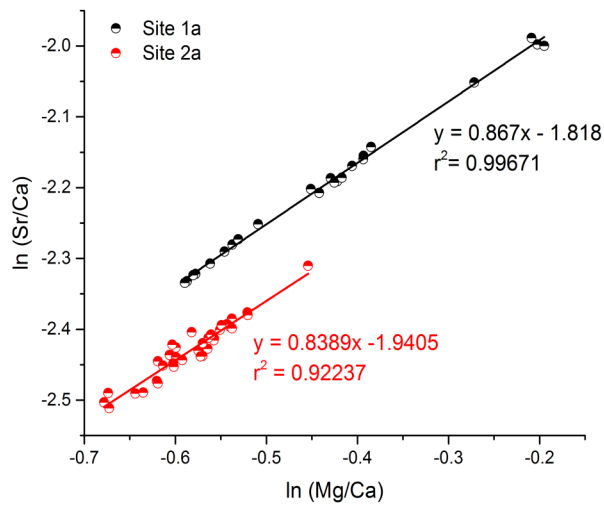

Figure 5. (a) A time series of $\ln (\mathrm{Sr} / \mathrm{Ca})$ vs. $\ln (\mathrm{Mg} / \mathrm{Ca})$. Site 1 a shows a clear enrichment in $\mathrm{Mg} / \mathrm{Ca}$ and $\mathrm{Sr} / \mathrm{Ca}$, or an increase in $\mathrm{PCP}$, post2007 , driven by evaporation. Site $2 \mathrm{a}$, on the other hand, shows quasi-seasonal variational in $\ln (\mathrm{Mg} / \mathrm{Ca})$ and $\ln (\mathrm{Sr} / \mathrm{Ca})$, suggesting here PCP is likely dominated by seasonality. (b) Shows that at both sites, $\ln (\mathrm{Mg} / \mathrm{Ca})$ vs. $\ln (\mathrm{Sr} / \mathrm{Ca})$, fall within the diagnostic range of PCP (a slope of + or -0.88 ) suggesting PCP is occurring.

suggesting that additional processes are specifically affecting $\mathrm{Ca}$. The rise in $\mathrm{Mg} / \mathrm{Ca}$ at Site 1a strongly suggests that the remaining portion of the Ca decline may be attributed to PCP (Fig. 5a).

At Site $2 \mathrm{a}$, a rising trend, reflects the concentration of solutes due to a rise in post-fire evapotranspiration, evidenced by increasing $\delta^{18} \mathrm{O}$ and $\mathrm{Cl}$, evaporation of near-surface water stores (Fig. $2 \mathrm{f}-\mathrm{h}$ ), and possibly, to some extent, an increase in transpiration from vegetation recovery for $\mathrm{Cl}$ (Treble et al., 2016). Additionally, Ca concentrations also show a quasiseasonal response, interpreted from the $\mathrm{Mg} / \mathrm{Ca}$ time series to be driven by PCP, possibly due to seasonal $P$ - AET (supported by similar seasonality in dripwater $\delta^{18} \mathrm{O}$; Fig. 2c) although in-cave PCP could also be contributing (Treble et al., 2015).

Sulfate and K post-fire at Site 1a are abnormally high in concentration, approximately 3 times higher in comparison to Site 2a (Fig. 2h and i; Tables 1 and 2). This is counterintuitive to the initial dilution signal (owing to a decrease in tree water use) interpreted for the other solutes. While at Site 2a, $\mathrm{SO}_{4}$ and $\mathrm{K}$ increase similar to other solutes, consistent with evaporative concentration (from post-fire conditions) and an increase in transpiration (from vegetation recovery). These observations suggest that there was an increase in the availability of $\mathrm{SO}_{4}$ and $\mathrm{K}$ after the fire at Site 1a despite a decrease in tree-water use here (Fig. $2 \mathrm{~h}$ and i).

We note the majority of above-ground $\mathrm{SO}_{4}$ is predominantly stored within the lower to middle storey of the for- est (O'Connell and Grove, 1996), and post-fire soils contain $23 \%$ more $\mathrm{S}$ and $16 \%$ more $\mathrm{K}$ than pre-fire soils due to biomass-sourced ash deposition (Grove et al., 1986). Therefore, $\mathrm{SO}_{4}$ and $\mathrm{K}$ concentrations at each site may respond differently since the amount of available $\mathrm{SO}_{4}$ and $\mathrm{K}$ above each site is influenced by the amount of biomass burnt above the site. Further, the dissolution rates of ash minerals containing these elements could also affect the rate at which these nutrients are leached from the surface and subsurface and subsequently their concentrations in dripwaters. We propose that the large amount of biomass burnt above Site 1a the tuart tree - is responsible for the much higher concentrations of $\mathrm{SO}_{4}$ and $\mathrm{K}$ at Site 1a dripwater relative to Site 2a. We also propose that the increase in near-surface evaporation from 2007 onwards drives even higher concentrations of $\mathrm{SO}_{4}$ and $\mathrm{K}$ (Fig. $2 \mathrm{~h}$ and i). Site 2a, which has much less pre-fire biomass, has much lower $\mathrm{SO}_{4}$ and $\mathrm{K}$ concentrations, consistent with our argument. Here, these solutes show a steady increasing trend over the monitoring period. This is consistent with increased evapotranspiration post-fire, which is also evident in the other solutes.

Now, we compare our Yonderup Cave results to those of Golgotha Cave to put $\mathrm{SO}_{4}$ and $\mathrm{K}$ concentrations into context. Golgotha Cave, last experienced a wildfire in 1992 and a controlled low-temperature prescribed burn in 2006, while Yonderup experienced a high intensity burn in 2005. First, we see 5 and 10 times higher within-cave differences in $\mathrm{SO}_{4}$ and $\mathrm{K}$ (respectively) at Yonderup Cave than we do at Golgo- 


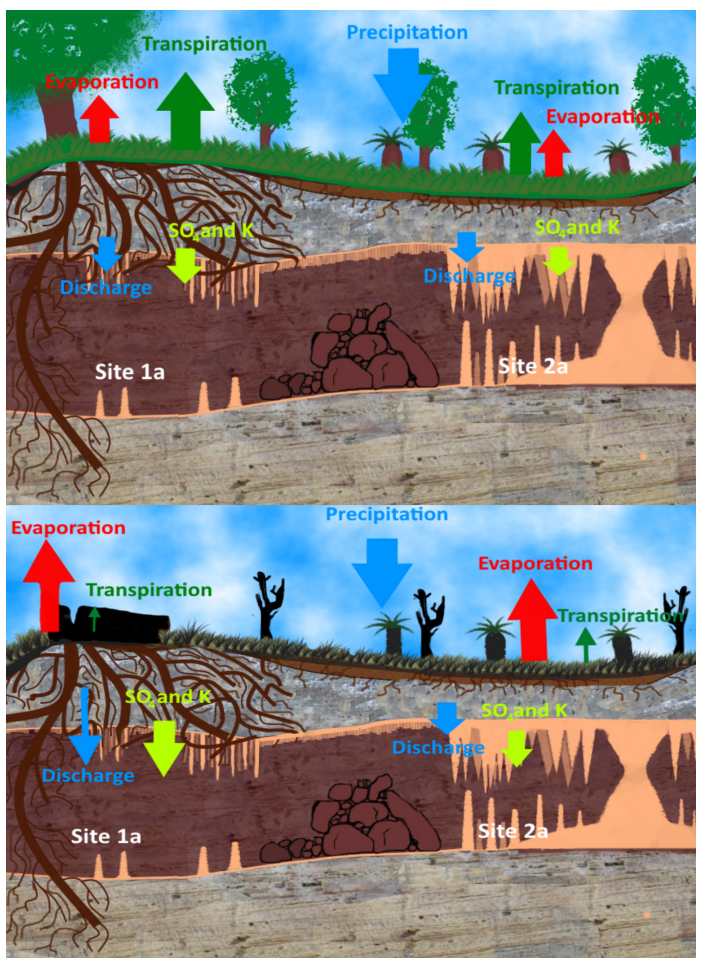

Figure 6. Evaporation (red) increases post-fire at both sites due to a reduction in albedo and vegetation cover, whereas precipitation (blue) remains the same and initial transpiration (green) decreases, but recovers over time. Site $2 \mathrm{a}$ shows higher $\delta^{18} \mathrm{O}$ and an increase in concentrations of solutes including $\mathrm{SO}_{4}$ and $\mathrm{K}$ (lime) due to evaporation and slow increase in transpiration due to vegetation recovery, with cumulative water balance (CWB) remaining the same. While Site 1a shows higher $\delta^{18} \mathrm{O}$ in response to increased evaporation and a decline in solute concentrations in response to increased discharge and a decrease in transpiration and removal of nutrients from the surface and subsurface. However, since $\mathrm{SO}_{4}$ and $\mathrm{K}$ are from biomass-sourced ash, the tuart tree above this site acts as a source of increased $\mathrm{SO}_{4}$ and $\mathrm{K}$. Discharge increased immediately (blue). But the drip became inactive 1 year after the fire due to an increase in evaporation, which outweighed the reduction in transpiration (green), leading to depletion of the near-surface reservoir feeding Site 1a and an inactive drip site.

tha Cave (Table 2). Also, concentrations at Yonderup Cave are up to 4 and 3 times higher in $\mathrm{SO}_{4}$ and $\mathrm{K}$, respectively, at Yonderup Cave than at Golgotha Cave (Table 1). These results coupled with the difference between $\mathrm{Cl}$ compositions at Yonderup vs. Golgotha presents a clear case for more variability in burnt sites in comparison to unburnt sites.

\subsection{A multi-proxy fire signal in dripwater}

Here we propose post-fire scenarios for both sites at Yonderup Cave (refer to conceptual model Fig. 6) that account for the altered dripwater chemistry that is observed postwildfire. A straight-forward relationship between CWB, discharge, and $\mathrm{Cl}$ concentrations at Site 2a suggests increased concentration of solutes $\left(\mathrm{Ca}, \mathrm{Mg}, \mathrm{Sr}, \mathrm{K}\right.$, and $\left.\mathrm{SO}_{4}\right)$ in response to an increase in near-surface evaporation (Fig. $2 \mathrm{c}$ and d).

In contrast solutes such as $\mathrm{Cl}, \mathrm{Mg}, \mathrm{Sr}$, and $\mathrm{Ca}$ at Site 1a show a declining trend. We have argued that this declining trend in these solutes is due to two underlying processes. First, a decrease in tree water use (transpiration) due to the death of the tuart tree in the wildfire. Tuart trees are deeply rooted, having adapted their root systems to access water from both the surface and subsurface. These roots have been found to generate potential energy between the tree and the soil to extract water and nutrients. Specifically, mature tuart trees generate a pressure gradient ranging from $-0.86 \pm 0.11 \mathrm{MPa}$ (summer) to $-0.35 \pm 0.02 \mathrm{MPa}$ (winter) (Drake et al., 2011). So the death of the tuart tree in the wildfire had a significant local effect on hydrology at Site 1a resulting in an increase in discharge and dilution of solutes $(\mathrm{Cl}$, $\mathrm{Mg}, \mathrm{Sr}$, and $\mathrm{Ca}$ ). Our study suggests that the consequent reduction in transpiration may not be immediately detected in dripwater, owing to transit time through the limestone and the requirement for overcoming a soil moisture deficit during drier than average climatic conditions. Hydrological effects, such as "capillary barriers", can also slow down vertical transport of infiltrating waters at our site (Mahmud et al., 2016).

Second, the decline in solutes at Site 1a could be the result of a gradual return to pre-fire concentrations following a pulse of increased input of solutes from ash (e.g. Site 1a scenario). A contribution of $\mathrm{SO}_{4}$ and $\mathrm{K}$ from burnt biomass may explain their relatively high concentrations.

Further, isotopic composition at Site 1a shows that $\delta^{18} \mathrm{O}$ is offset from modelled hydro-climatic $\delta^{18} \mathrm{O}$ by $\sim+1 \%$ o suggesting increased near-surface evaporation post-fire, which we attribute to the reduction of shading from the tuart tree post-fire - even in $P>$ AET periods (Fig. 2c); post-2007, when $P<$ AET conditions arrive, $\delta^{18} \mathrm{O}$ rises even higher and discharge declines. Eventually, due to the persistent duration of $P<$ AET conditions, Site 1a ceased dripping owing to eventual depletion of the near-surface reservoir feeding this drip.

Site $2 \mathrm{a}$ also shows higher $\delta^{18} \mathrm{O}$ during the post-fire period, which we attribute to an increase in near-surface evaporation as a result of low albedo and reduced vegetation cover. The case for evaporation at this site is supported by the rise in $\mathrm{Cl}$ and other solutes. The possibility of an immediate spike in solutes from ash and a long-term decline from leaching, as was discussed for Site 1a, is limited here, as there was less biomass available to burn above Site 2a. Therefore, we interpret increased evaporation and transpiration from regrowth post-fire to be the dominant forcing at this site, similar to the findings of Treble et al. (2016).

We propose that differences in surface vegetation above sites can influence site specific drip chemistry. For example, we interpret Site 1a was influenced by a reduction in transpiration after the fire, due to the forcing biomass above the site, which may also have been a source of post-fire ash at this site. 
At Site $2 \mathrm{a}$ the response to the fire was primarily an increase in near-surface evaporation owing to changes in surface albedo. This variability within the cave response at Yonderup Cave is significant, so too is the comparison between Yonderup Cave drip chemistry and the drip chemistry at Golgotha Cave. The latter more generally highlights that an intense wildfire has variable yet multi-year effects on dripwater composition in shallow caves.

From this we propose that post-fire condition persist upto 5-10 years' post-fire, affecting dripwater $\delta^{18} \mathrm{O}$ and solute concentrations. We would expect a full recovery, of $\delta^{18} \mathrm{O}$ and solute concentrations back to pre-fire levels within 1020 years as a result of revegetation growth (Treble et al., 2016) and re-establishment of vegetation cover and pre-fire albedo.

\section{Application for a speleothem palaeo-fire signal}

Our post-wildfire dripwater response from $\delta^{18} \mathrm{O}$ was a $2 \%$ increase above that predicted by a hydro-climatic model, and measured regional groundwater and Golgotha Cave $\delta^{18} \mathrm{O}$ data. If this signal is preserved at equilibrium in speleothems this is equivalent to some of the largest interpreted climatic changes seen in the Quaternary record. This highlights the significance of the findings in our study, which suggests a fire signal could in fact be misinterpreted as climate variability. Furthermore, the impact of the decrease in Ca dissolution from the limestone bedrock could have a significant effect on speleothem growth rate.

However, before attributing $\delta^{18} \mathrm{O}$ and growth rate abnormalities to fire, we must remember there are a number of processes that effect speleothem $\delta^{18} \mathrm{O}$. Thus, it is important that a multi-proxy approach, which uses isotopic composition as well as a suite of trace elements (sourced from both soil and bedrock), is used to separate fire from other forcings such as climate and other local factors. Further, our study was conducted in a shallow cave environment, where perhaps the overlying vegetation can exert a more dominant forcing on dripwater hydrology and chemistry relative to deeper caves. Deeper caves have more complex hydrology (McDonald and Drysdale, 2007); this involves mixing with other flow paths, which are possibly not fire affected. This may result in the smoothing of the fire signal; making it harder to isolate. Further, a fire signal in cave dripwater and stalagmites may be much subtler in a grassland environment in comparison to a forested environment as changes in the biomass would be smaller and vegetation recovery presumably faster (Coleborn et al., 2016). We recommend searching for fire signals in shallow cave environments in the tree rooting zone in forested areas.

One further approach that may help to differentiate fire and climate signals in a stalagmite would be to use multivariate statistical techniques such as principal component analyses (PCA). Using this technique, we would expect one com- ponent to reflect a bedrock/hydro-climatic signal and another to preserve a local soil/vegetative forcing. The soil/vegetative component could preserve the impact of a fire on stalagmite composition, in trace elements like $\mathrm{S}$ and $\mathrm{K}$. Further, it is also possible an immediate spike in solutes $(\mathrm{Mg}, \mathrm{Ca}, \mathrm{Cl}, \mathrm{Sr}, \mathrm{S}, \mathrm{K}$, and $\mathrm{P}$ ) from post-fire ash may be preserved in stalagmites and colloid-associated metals, such as $\mathrm{Al}, \mathrm{Fe}$, and $\mathrm{Cu}$ from an increase in discharge post-fire. Future studies of this kind will open a new avenue in speleothem research: speleothems as archives of palaeo-fire.

\section{Conclusions}

We isolate a post-wildfire response by comparing a recently burnt cave monitoring site with forward modelled $\delta^{18} \mathrm{O}$, which predicts $\delta^{18} \mathrm{O}$ based on hydro-climatic factors, and nearby cave monitoring and groundwater data. We provide a novel analysis of the multi-year impacts wildfire has on cave dripwater. Our analysis shows a strong hydrologic relationship between surface environments and shallow caves that are located within the tree rooting zone. This finding is especially important in water-limited environments $(P<\mathrm{ET})$ as the overlying vegetation can exert controls on the cave hydrogeochemical environment.

A post-wildfire dripwater response is clearest in $\delta^{18} \mathrm{O}$ and $\mathrm{Cl}$ due to their sensitivity to variation in near-surface evaporation (both $\delta^{18} \mathrm{O}$ and $\mathrm{Cl}$ ) and transpiration $(\mathrm{Cl}) . \mathrm{Cl}$ is a conservative ion and hence is driven mainly by dilution/evaporation. $\mathrm{Cl}$ declines post-fire at Site $1 \mathrm{a}$, which we interpret as dilution of the water store that the dead tree previously exploited. In contrast, $\mathrm{Cl}$ increases at Site 2a, sympathetically with $\delta^{18} \mathrm{O}$, consistent with an increased evaporative demand on shallow water stores driven by post-fire reduction in shading and reduced albedo. $\mathrm{SO}_{4}$ and $\mathrm{K}$ are also important at sites with abundant biomass as they can be leached at high concentrations because they are made more abundant in postfire soils due to the ash generated from a fire. Other solutes such as $\mathrm{Mg}$, Sr, and $\mathrm{Ca}$ support the dominant local forcing at the site post-fire and can be extremely powerful when using a multi-proxy approach.

We propose a conceptual model for a multi-year postwildfire cave dripwater response in forested water-limited regions. This involves a 5-10-year response of (1) higher $\delta^{18} \mathrm{O}$ and $\mathrm{Cl}$ in cave dripwater due to increased evaporation and decreased shading after the wildfire; (2) increased $\mathrm{K}$ and $\mathrm{SO}_{4}$ due to the leaching of biomass-sourced ash, particularly in areas with large biomass; and (3) increased variability in $\mathrm{Mg}, \mathrm{Sr}$, and $\mathrm{Ca}$ due to changes in evaporation, transpiration and water-rock interactions post-fire. We may expect a recovery within 10-20 years after the wildfire and a return to to pre-fire isotopic and trace element concentrations as a result of increased bio-productivity from forest regrowth and a re-establishment of canopy cover. 


\section{The Supplement related to this article is available online at doi:10.5194/hess-20-2745-2016-supplement.}

Acknowledgements. Many thanks must go to the team at Yanchep National Park, especially Ciara McDuff, Rob Foulds, and Gary Hunton for your assistance with the data collection. We also acknowledge ANSTO staff: Alan Griffith (AWAP data access), Suzanne Hollins for permission to use unpublished Perth rainfall isotopic data, Henri Wong, Scott Allchin, and Barbora Gallager for dripwater analyses, as well as Michael Gagan and Joan Cowley for assistance with water isotopes at ANU. This research was in part funded by ARC Linkage LP13010017 and Land \& Water Australia grant (ANU52) to Pauline C. Treble. The outcomes of this study contribute to ARC Discovery Project DP140102059 awarded to Pauline C. Treble. This research was also supported by the AINSE honours scholarship program awarded to Gurinder Nagra. Finally, we also thank the three anonymous reviewers for their constructive questions and suggestions.

Edited by: A. Butturini

\section{References}

Abbott, I. and Burrows, N.: Fire in ecosystems of south-west Western Australia: impacts and management, Backhuys Publishers, Leiden, the Netherlands, 2003.

Baker, A. and Bradley, C.: Modern stalagmite $\delta^{18} \mathrm{O}$ : Instrumental calibration and forward modelling, Global Planet. Change, 71, 201-206, doi:10.1016/j.gloplacha.2009.05.002, 2010.

Baker, A., Asrat, A., Fairchild, I. J., Leng, M. J., Thomas, L., Widmann, M., Jex, C. N., Dong, B., van Calsteren, P., and Bryant, C.: Decadal-scale rainfall variability in Ethiopia recorded in an annually laminated, Holocene-age, stalagmite, Holocene, 20, $827-$ 836, 2010

Breecker, D. O., Payne, A. E., Quade, J., Banner, J. L., Ball, C. E., Ball, C. E., Meyer, K. W., and Cowan, B. D.: The sources and sinks of $\mathrm{CO}_{2}$ and mixed woodland in grassland vegetation, Geochim. Cosmochim. Ac., 96, 230-246, doi:10.1016/j.gca.2012.08.023, 2012.

Coleborn, K., Spate, A., Tozer, M., Andersen, M. S., Fairchild, I. J., MacKenzie, B., Treble, P. C., Meehan, S., Baker, A., and Baker, A.: Effects of wildfire on long-term soil $\mathrm{CO}_{2}$ concentration: Implications for karst processes, Environ. Earth Sci., 75, $1-12,2016$.

Collister, C. and Mattey, D.: Controls on drop volume at speleothem drip sites: An experimental study, J. Hydrol., 358, 259-267, 2008.

Cuthbert, M. O., Baker, A., Jex, C. N., Graham, P. W.,Treble, P. C., Andersen, M. S., and Ian Acworth, R.: Drip water isotopes in semi-arid karst: Implications for speleothem plaeoclimatlogy, Earth Planet. Sc. Lett., 395, 194-204, doi:10.1016/j.epsl.2014.03.034, 2014

Drake, P. L., Froend, R. H., and Franks, P. J.: Linking hydraulic conductivity and photosynthesis to water-source partitioning in trees versus seedlings, Tree Physiol., 31, 763-773, 2011.

Fairchild, I. J. and Baker, A.: Speleothem Science: From process to Past Environments, Wiley-Blackwell, 2012.
Fairchild, I. J. and Treble, P. C.: Trace elements in speleothems as recorders of environmetal change, Quaternary Sci. Rev., 28, 449468, doi:10.1016/j.quascirev.2008.11.007, 2009.

Fairchild, I. J., Borsato, A., Tooth, A. F., Frisia, S., Hawkesworth, C. J., Huang, Y., McDermott, F., and Spiro, B.: Controls on trace element (Sr-Mg) compositions of carbonate cave waters: implications for spelothem climatic records, Chem. Geol., 166, 255269, doi:10.1016/S0009-2541(99)00216-8, 2000.

Gonzalez-Pelayo, O., Andreu, V., Gimeno-Garcia, E., Campo, J., and Rubio, J. L.: Effects of fire and vegetation cover on hydrological characteristics of a Mediterranean shrubland soil, Hydrol Process., 24, 1504-1513, doi:10.1002/hyp.7612, 2010.

Graedel, T. E. and Keene, W. C.: The budget and cycle of Earth's natural chlorine, Pure Appl. Chem., 68, 1689-1697, 1996.

Grove, T. S., O'Connell, A. M., and Dimmock, G. M.: Nutrient changes in surface soils after an intense fire in jarrah (Eucalyptus marginata) forest, Aust. J. Ecol., 11, 303-317, 1986.

Hingston, F. J. and Gailitis, V.: The geographic variation of salt precipitated over Western Australia, Aust. J. Soil Res., 14, 319-335, 1976.

Hughes, C. E. and Crawford, J.: A new precipitation weighted method for determining the metoric water line for hydrological applications demonstrated using Australian and GNIP data, J. Hydrol., 344-351, doi:10.1016/j.jhydrol.2012.07.029, 2012.

Hurst, H.: Methods of long-term storage in reservoirs, T. Am. Soc. Civ. Eng., 116, 519-543, 1951.

Jennings, J. N.: Syngenetic Karstsin Australia, in: Contributions to the study of Karst, edited by: Williams, P. W. and Jennings, J. N., Department of Geography Publication G/5, Australian National University, 41-110, 1964.

Lachinet, M. S.: Climatic and environmental controld on speleothem oxygen-isotope values, Quaternary Sci. Rev., 28, 412-432, doi:10.1016/j.quascirev.2008.10.021, 2009.

Mahmud, K., Mariethoz, G., Baker, A., Treble, P. C., Markowska, M., and McGuire, E.: Estimation of deep infiltration in unsaturated limestone environments using cave lidar and drip count data, Hydrol. Earth Syst. Sci., 20, 359-373, doi:10.5194/hess20-359-2016, 2016.

McDermott, F., Mattey, D. P., and Hawkesworth, C.: Centennialscale Holocene climate variability revealed by a high-resolution speleothem $\delta^{18}$ O Record from SW Ireland, Science, 294, 13281332, 2001.

McDonald, J. and Drysdale, R.: Hydrology of cave drip waters at varying bedrock depths from a karst system in southeastern Australia, Hydrol. Process., 21, 1737-1748, doi:10.1002/hyp.6356, 2007.

O'Connell, A. M. and Grove, T. S.: Biomass production, nutrient uptake and nutrient cycling in the jarrah and karri forests of south-western Australia, in: Nutrition of Eucalypts, CSIRO publishing, Collingwood, Australia, 155-189, 1996.

Pape, J. R., Banner, J. L., Mack, L. E., Musgrove, M., and Guilfoyle, A.: Controls on oxygen isotope variability in precipitation and cave drip waters, central Texas, USA, J. Hydrol., 385, 203-215, doi:10.1016/j.jhydrol.2010.02.021, 2010.

Raupach, M. R., Briggs, P. R., Haverd, V., King, E. A., Paget, M., and Trudinger, C. M.: Australian Water Availability Project (AWAP), Final Report for Phase 3, CSIRO Marine and Atmospheric Research Component, CSIRO, Collingwood, Australia, 1-72, 2009. 
Raupach, M. R., Harman, I. N., and Canadell, J. G.: Global climate goals for temperature, concentrations, emissions and cumulative emissions, CSIRO CAWCR Technical Report no. 42, CSIRO, Collingwood, Australia, 1-55, 2011.

Rutlidge, H., Baker, A., Marjo, C. E., Andersen, M. S., Graham, P. W., Cuthbert, M. O., Rau, G. C., Roshan, H., Markowska, M., Marithoz, G., and Jex, C. N.: Dripwater organic matter and trace element geochemistry in a semi-arid karst environment: Implications for speleothem paleoclimatology, Geochim. Cosmochim. Ac., 135, 217-230, doi:10.1016/j.gca.2014.03.036, 2014.

Silberstein, R. P., Dawes, W. R., Bastow, T. P., Byrne, J., and Smart, N. F.: Evaluation of post-fire recharge under native woodland using hydrological measurements, modelling and remote sensing: J. Hydrol., 489, 1-15, 2013.

Sinclair, D. J.: Two mathematical models of $\mathrm{Mg}$ and $\mathrm{Sr}$ partitioning into solution during incongruent calcite dissolution, Chem. Geol., 283, 119-133, 2011.

Tooth, A. F. and Fairchild, I. J.: Soil and karst aquifer hydrological controls on the geochemical evolution of speleothem-forming drip waters, Crag Cave, southwest Ireland, J. Hydrol., 273, 5168, doi:10.1016/S0022-1694(02)00349-9, 2003.

Treble, P. C., Fairchild, I. J., and Fischer, M.: Understanding climate proxies in southwest-Australian speleothems, PAGES News, 16, 17-19, 2008.

Treble, P. C., Bradley, C., Wood, A., Baker, A., Jex, C. N., Fairchild, I. J., Gagan, M. K., Cowley, J., and Azcurra, C.: An isotopic and modelling study of flow paths and storage in Quaternary calcarenite, SW australia: implications for speleothem paleoclimate records, Quaternary Sci. Rev., 64, 90103, doi:10.1016/j.quascirev.2012.12.015, 2013.

Treble, P. C., Fairchild, I. J., Griffiths, A., Baker, A., Meredith, K. T., Wood, A., and McGuire, E.: Impacts of cave air ventilation and in-cave prior calcite precipitation on Golgotha cave drip water chemistry, southwest Australia, Quaternary Sci. Rev., 127, 6172, doi:10.1016/j.quascirev.2015.06.001, 2015.

Treble, P. C., Fairchild, I. J., Baker, A., Meredith, K. M., Andersen, M. S., Salmon, S. U., Bradley, C., Wynn, P. M., Hankin, S., Wood, A., and McGuire, E.: Roles of bioproductivity, transpiration and fire in an eight-year record of cave dripwater chemistry from a forested catchment, southwest Australia. Geochim. Cosmochim. Ac., 184, 132-150, doi:10.1016/j.gca.2016.04.017, 2016.
Tremaine, M. D. and Froelich, N. P.: Speleothem trace element signatures: A hyrologic geochemical study of modern cave dripwaters and farmed calcite, Geochim. Cosmochim. Ac., 121, 522545, doi:10.1016/j.gca.2013.07.026, 2013.

Turner, J. V. and Thorpe, P. M.: Paleotemperature conditions for the southwest of Western Australia from the stable isotopic composition of deep, confined groundwater within the Perth Basin, Proceedings of International Conference on the Study of Environmental Change using isotope techniques, 23-26 April 2001, IAEA, Vienna, 504-508, 2001.

Turner, J. V., Arad, A., and Johston, C. D.: Environmental isotope hydrology of salanized experimetal catchments, J. Hydrol., 94, 89-107, doi:10.1016/0022-1694(87)90034-5, 1987.

Watts, A. R. and Henley, P. W.: Map of Yonderup Cave, Cave Research Group, scale $1: 100,1973$.

Wong, C. I. and Banner, J. L.: Response of cave air $\mathrm{CO}_{2}$ and drip water to brush clearing in central Texas: Implications for recharge and soil $\mathrm{CO}_{2}$ dynamics, J. Geophys. Res., 115, 1-13, doi:10.1029/2010JG001301, 2010.

Wong, C. I., Banner, J. L., and Musgrove, M.: Seasonal dripwater $\mathrm{Mg} / \mathrm{Ca}$ and $\mathrm{Sr} / \mathrm{Ca}$ variations driven by cave ventilation: Implications for and modeling of speleothem paleoclimate records, Geochim. Cosmochim. Ac., 468, 159-172, doi:10.1016/j.gca.2011.03.025, 2011.

Woodhead, J., Reisz, R., Fox, D., Drysdale, R., Hellstrom, J., Maas, R., Cheng, H., and Edwards, R. L.: Speleothem climate records from deep time? Exploring the potential with an example from the Permian, Geology, 38, 455-458, 2010.

Yusiharni, E. and Gilkes, R. J.: Changes in the mineralogy and chemistry of a lateritis soil due to a bushfire at Wundowie, Darling Range, Western Australia, Geoderma, 191, 140-150, doi:10.1016/j.geoderma.2012.01.030, 2012a.

Yusiharni, E. and Gilkes, R. J.: Minerals in the ash of Australian native plants, Geoderma, 189-190, 369-380, 2012b. 